\title{
Antoine-Marin Lemierre, Guillaume Tell. Tragédie
}

\section{Wilma Proglio}

\section{(2) OpenEdition}

\section{Journals}

\section{Edizione digitale}

URL: http://journals.openedition.org/studifrancesi/27637

DOI: 10.4000/studifrancesi.27637

ISSN: 2421-5856

\section{Editore}

Rosenberg \& Sellier

\section{Edizione cartacea}

Data di pubblicazione: 31 décembre 2006

Paginazione: 608-609

ISSN: 0039-2944

\section{Notizia bibliografica digitale}

Wilma Proglio, « Antoine-Marin Lemierre, Guillaume Tell. Tragédie », Studi Francesi [Online], 150 (L | III) | 2006, online dal 30 novembre 2015, consultato il 08 novembre 2020. URL : http://

journals.openedition.org/studifrancesi/27637 ; DOI : https://doi.org/10.4000/studifrancesi.27637

\section{Questo documento è stato generato automaticamente il 8 novembre 2020.}

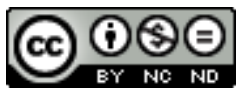

Studi Francesi è distribuita con Licenza Creative Commons Attribuzione - Non commerciale - Non opere derivate 4.0 Internazionale. 


\title{
Antoine-Marin Lemierre, Guillaume Tell. Tragédie
}

\author{
Wilma Proglio
}

\section{NOTIZIA}

ANTOINE-MARIN LEMIERRE, Guillaume Tell. Tragédie. Etablissement du texte, introduction et notes par Renaud BRET-VITOZ. Préface de Pierre FRANTZ, Rennes, PUR, 2005, pp. 198.

1 «Le premier Guillaume Tell - qui s'en souvient? - est français. Lemierre a précédé Schiller, Sedaine et Rossini». Con queste parole della prefazione Pierre Frantz suggerisce immediatamente l'importanza del volume, con il quale Renaud Bret-Vitoz ripropone un testo teatrale che ebbe un grande successo nella seconda metà del Settecento, per poi cadere, insieme con il poeta, in un ingiusto oblio. Nell'Introduzione l'autore ripercorre la storia della pièce, la quale conobbe quattro diverse edizioni tra il 1767 ed il 1793. Accolta con freddezza nella sua prima versione, la tragedia destò grande entusiasmo a partire dalla rappresentazione del 1786, nella quale venne portato in scena l'episodio della prova della mela, fino ad allora relegata dietro le quinte, secondo i dettami della tragediografia classica. Questa pièce segnò una tappa molto importante nel processo di trasformazione che investì l'arte drammatica verso la fine del XVIII secolo; in particolare il successo della prova della mela sancì l'avvento di una nuova estetica, nella quale l'azione ha il sopravvento sulla narrazione. A ciò si accompagna l'importanza della scenografia (firmata dal grande Brunetti) e l'attenzione alla resa del colore locale, aspetti sempre più curati dallo stesso Lemierre in ogni versione della sua pièce. La spettacolarità ed il grande impatto visivo delle tragedie di questo autore valsero loro, da parte di La Harpe, la definizione di «tragédies faites à peindre». Il soggetto di Guillaune Tell è inoltre alquanto insolito, dal momento che non mette in scena personaggi classici, bensì facendo proprio un certo gusto volteriano per il bizzarro e l'esotico, uomini di umili origini e di tradizioni piuttosto sconosciute ai francesi. 
2 Lemierre, tuttavia, non si limitò a scrivere una tragedia di costume e di sapore pastorale, dal momento che egli, in realtà, si dimostrò un poeta politico, facendo dialogare i suoi personaggi su temi quali la libertà, la ribellione all'oppressione e la lotta contro il potere arbitrario. Indubbio il contenuto rivoluzionario di questa tragedia, che sfuggì al veto della censura in quanto la rivolta popolare non era rivolta contro il sovrano bensì contro Gessler, suo inflessibile rappresentante. A differenza del successivo Guglielmo Tell di Schiller, il quale agisce solo per difendere la propria famiglia, senza finalità politiche o civili, quello di Lemierre è un personaggio consapevole della portata delle proprie azioni e che deliberatamente sceglie di opporsi al tiranno.

Il cuore del volume è l'edizione critica della tragedia di Lemierre, presentata nella versione del 1793 e corredata di un vasto apparato di note nelle quali Bret-Vitoz specifica le varianti del testo rispetto alle edizioni precedenti $(1767,1776,1787)$. Il lettore può dunque seguire con grande chiarezza l'evoluzione dell'estetica drammaturgica di Lemierre: da una pièce di impostazione inizialmente tradizionale ad un testo in cui l'azione, la gestualità e l'ambientazione assumono via via sempre maggiore importanza. Di notevole interesse e ricchezza è però anche la parte degli Annexes. In questo settore l'autore propone integralmente la scena della mela nella versione della tragedia del 1787 ed una versione apocrifa e anonima della medesima scena, datata 1794. Egli riporta poi la descrizione originale della scenografia di Brunetti (particolarmente elaborata e costosa per il tempo) ed alcuni estratti dei rapporti del comitato di censura, redatti nel 1827-1828. La posizione più significativa è quella di La Forest, che si dichiarò propenso alla rappresentazione della tragedia di Lemierre nell'adattamento di Pichat, mentre si oppose aspramente all'eventualità di mettere in scena la medesima vicenda al Théâtre de la Gaité, nella versione melodrammatica di Guîlbert de Pixerécourt, per il timore di infiammare nuovamente l'animo popolare. Nell'allegato successivo Bret-Vitoz riporta la scena della mela presente proprio nella versione di Pixerécourt, decisamente più patetica ed enfatica di quella di Lemierre. Chiudono questa sezione alcune notizie storiche su Tell ed un esauriente elenco di tutte le opere, letterarie, teatrali e non, aventi per protagonista l'eroe svizzero. Chiude il testo una ricca bibliografia. 